\title{
Psychological Capital, Emotional Labor and Counterproductive Work Behavior of Service Employees: The Moderating Role of Leaders' Emotional Intelligence
}

\author{
Xiaodan Wang, Xiaotong Lian \\ Business School, Northeast Normal University, Changchun, China \\ Email: wangxd415@nenu.edu.cn, 562164404@qq.com
}

Received 27 May 2015; accepted 23 June 2015; published 26 June 2015

Copyright (C) 2015 by authors and Scientific Research Publishing Inc.

This work is licensed under the Creative Commons Attribution International License (CC BY). http://creativecommons.org/licenses/by/4.0/

(c) (i) Open Access

\begin{abstract}
Based on the perspective of service employees psychological capital, this study adopts questionnaire survey, with every 218 employees of service industry of Jilin province as samples, to examine the Chinese services employees' psychological capital influence on counterproductive work behavior, and explore the mediation role of emotional labor (surface and deep acting) and the moderating role of leaders' emotional intelligence. The results show that the service sector employees' psychological capital is significantly negative correlated with counterproductive work behavior, deep acting plays the mediation role between the two, and that leaders' emotional intelligence plays the moderating role between deep acting and the counterproductive work behavior. This study provides valuable theoretical bases and feasible solutions for preventing and controlling staff's counterproductive work behavior caused by psychological capital timely and effectively.
\end{abstract}

\section{Keywords}

Service Employees, CWB, Psychological Capital, Emotional Labor, Emotional Intelligence

\section{Introduction}

With the depth of economic reform, China's economic structure is undergoing great changes and the services sector in the industrial structure is becoming more promoted. According to the National Bureau of Statistics data, the percent of the first half of 2014's GDP was $46.6 \%$, which had already been more than the second industry. Seen as an emerging service industry, it is becoming a powerful force that enhances the country's economic 
strength. However, with the steady development of the service sector, the problems in the industry are also increasing. Thousands of teachers of Heilongjiang and Henan Province stroke in November and December of 2014, leading to a spate of city schools closed. Ku6.com had conflicts due to collective layoffs in 2011. A doctor of a Nanjing hospital was busy on his private affairs, so that a child who was over 5 months died in 2009. In 2008, China Eastern Airlines 18 flights returning make huge losses and so on [1]. In addition to the large media coverage of these hot, employees play games, chat, lie down on the job, provoke the relationship among colleagues, and say bad things about leaders, and other small phenomena in work time are common. These destructive behaviors prevailing in the working environment can be called the "counterproductive work behavior (CWB)".

Counterproductive work behavior (CWB) is that employees violate the provisions of the organization, and threaten to organize and conduct the interests of members of other organizations intentionally and spontaneously, including theft, sabotage, miners, etc. [2]. There will be a series of restricting business development issues that not only affect the degree of harmonious labor relations, but also will lead to lower production efficiency, corporate social image damage, etc. [2]. For the service industry, its product is service, and its quality is even directly determined by the employee's behavior, so the behavior of employees is particularly important for service purposes. Compared with China, the foreign scholars studied CWB earlier and they had carried out extensive researches for businesses [3]-[5]. Our research started late and most researches were for manufacturing enterprises [6] [7]. Because CWB paid less attention to service workers, this paper studied CWB of service employees, analyzing influence factors of service employees' CWB by questionnaires and models.

\section{Models and Theoretical Hypothesises}

\subsection{Psychological Capital and Counterproductive Work Behavior}

Psychological capital is positive mental state in personal growth and development to encourage individuals to have a positive organizational behavior. It contains four elements of self-efficacy, hope, optimism and resilience [8]. The higher the level of active employees "psychological state (i.e., the higher the psychological capital), the stronger regulation of the internal working environment and interpersonal relationships, a positive impact on their own and others" work behavior generated greater; otherwise the impact of the small. For example, when faced with rude customers, employees who have high psychological capital will be more positive and optimistic to take the initiative to explore new initiatives and ways to change negative situations, rather than use CWB to deal with. In other words, employees who have high psychological capital is not easy to produce CWB [9]. Despite the different subjects, James (2008, 2010), Avey (2008), Steven (2010), Norman (2010), Bovine Kay Cloud (2012) and other scholars were also confirmed this result. Therefore, we propose the first hypothesis about CWB:

H1: Psychological capital of service employees has a negative impact on counterproductive work behavior.

\subsection{The Mediation Role of Emotional Labor}

Service companies generally require employees to be enthusiastic and polite in the work process, but employees may be difficult to do this because of various pressures or personal feelings and other factors, these all will lead to emotional labor. Emotional labor refers to "the process in which employees try to adjust their emotional feelings and emotions expressed in order to achieve the stated objectives of the organization". In order to achieve the desired emotional expression by organization, part of the staff only change their outward expression of their emotions and difficult to change their inner true feelings immediately, and this is called surface acting; Another part of the staff try to adjust and change their inner feelings to make their own feelings and external performance consistent, that is deep acting [10].

Employees who have high psychological capital will use positive attitude to face difficulties, to adjust the mood actively, to explore the new plan and way to change the passive situation. On the other hand, for employees who have low psychological capital, it's difficult to adjust their emotions in a short time, so they often just false display of affection and muddle along. It can be inferred that in service industry, the level of psychological capital will influence emotional labor strategy. Employees who have high psychological capital are more likely to make deep acting, on the contrary, employees who have low psychological capital are more likely to make surface acting. At the same time, employees who make surface acting try to express positive emotions and suppress negative emotions. The inconsistency of their emotion and behavior will make the self-authenticity damaged, prone to mental fatigue, emotional exhaustion and other negative psychological. Thus it is easy to 
produce CWB [11]. For employees who make deep acting, their feeling and emotional expression are consistent, so it will not promote CWB. Therefore, we put forward the second and third hypotheses:

H2a: Surface acting of service employees plays the mediation role between the psychological capital and counterproductive behavior.

H2b: Deep acting of service employees plays the mediation role between the psychological capital and counterproductive behavior.

\subsection{The Moderating Role of Leaders' Emotional Intelligence}

Emotional intelligence is a kind of ability which people use to effectively manage their emotions and feelings to guide their thoughts and actions [12]. Leaders' emotional intelligence in the organization, namely refers to the ability which leaders performance out of the understanding, control their own, evaluation and management of others' (especially subordinate) emotion and psychology and behavior with emotion related in the process of work and social interaction [13].

Specifically, for leadership of the high emotional intelligence, it's easier to understand and control of their own and employees' emotions and behaviors, and be able to communicate and help employees to solve the problem in the process of work. When employees choose surface acting in the working process, degree of their psychological exhaustion will be high. The leadership of the high emotional intelligence will perceive their exhaustion, adjust their mood and relieve their mental fatigue to reduce their CWB. When employees at work choose deep acting, high emotional intelligence leadership will perceive employees' sincerity and dedication, they will praise and care about them timely. Praise and understanding from leadership will also inhibit employees' CWB. Conversely, leaders who have low emotional intelligence cannot feel employees' emotions timely and accurately, so the mediation will be weakened and the influence will be small. Because in service industry, goods and services are the same, the service quality of employees is crucial. High emotional intelligence of leadership is precisely the powerful security services of employees. Therefore, we add leaders' emotional intelligence as the moderator into the model to explore the interactive effects of emotional labor and leaders' emotional intelligence on counterproductive work behavior in service industry and then we propose the forth and fifth hypothesis:

$\mathrm{H} 3 \mathrm{a}$ : In the high emotional intelligence organization, positive effect on the CWB from surface acting is weak; in the low emotional intelligence organization, positive effect on the CWB from surface acting is strong.

$\mathrm{H} 3 \mathrm{~b}$ : In the high emotional intelligence organization, negative effect on the CWB from deep acting is strong; in the low emotional intelligence organization, negative effect on the CWB from deep acting is weak.

Above all, we construct a theoretical model of our study, as shown in Figure 1.

\section{Method}

\subsection{Sample}

Samples selected for this study were derived from service industry of Jilin Province, including financial, food, communication, basic education and other industries, mainly distributed in Changchun, Baicheng, Siping, Yanbian Korean Autonomous Prefecture. The electronic questionnaire issued by email, Internet chat tools, chat client mobile phone and so on. Participants were asked to complete questionnaires anonymously. We collected information for three times, issued a total of 300 copies of questionnaires, recovered 227 copies of questionnaires. The response rate is $75.67 \%$. Then we removed some invalid questionnaires and recovered 218 copies of valid questionnaires finally.

In our survey, the proportion of men and women generally flat: the proportion of men accounted for $46.8 \%$

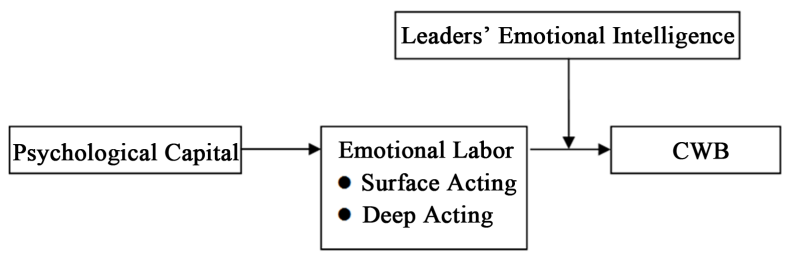

Figure 1. Framework. 
and women was $53.2 \%$. Age is mainly distributed in the $21-30$ years old $(37.2 \%)$ and the second distribution in $31-40(28.4 \%)$ and $41-50$ years old $(22.5 \%)$. Seen in this sample there are much younger workers. Sample average age of employees work mainly in five years (63.3\%). Employees and managers (including grassroots managers, middle managers and senior managers) accounted for $50.4 \%$ and $49.6 \%$. In addition, for industry where samples belong to, basic services (including communication and information services) account for $15.1 \%$, production and market services (including finance, intermediary and information, e-commerce and other professional services) account for $28.4 \%$, consumer services (including accommodation, catering, entertainment music, tourism, real estate) account for $31.7 \%$, and the public service industry (including the government's public management, medical, basic education, public information services, etc.) account for $24.8 \%$.

\subsection{Scale}

In order to ensure the reliability and validity of the scale, we choose scales which are mature and referenced repeatedly by scholars. According to the content and purpose of this study, we refer to the expert' opinion to delet and modify some specific questions and then we test the reliability, validity of the revised items.

1) Psychological capital scale

Psychological capital questionnaire (PCQ-24) we used is written by Luthans (2007), and translated by Li Chaoping (2008). This scale is the widely used in the study of the psychological capital. It has 24 items, using 5 point Likert scoring (1-strongly disagree, 5-strongly agree) [14]. Getting higher scores shows that the participant has higher psychological capital. Reliability coefficient (Cronbach's alpha) of the scale is 0.910 (>0.7). Except for 19th item, factor loading value of each item is greater than 0.5. Therefore, after removing the first 19th question, the average variance extracted (AVE) value is $0.542(>0.5)$ and composite reliability (CR) value is 0.947 $(>0.7)$. All these indicate that psychological capital scale has good reliability and validity.

2) Emotional labor scale

Emotional labor questionnaire we used is written by Grandy (2003), and translated by Lang Peijun (2003). The scale measures two dimensions: surface acting and deep acting. There are a total of 11 questions items [15]. On the basis of our research, we revised the scale and got a total of 6 items of the scale, of which 2 items to measure the surface acting, 4 items to measure deep acting. It is 5 point Likert scoring (1-strongly disagree, 5-strongly agree). Getting higher scores shows that the participant is more possibility to do surface acting or deep acting. Reliability coefficients (Cronbach's alpha) of the surface acting and deep acting scale are 0.712 and $0.860(>0.7)$ and factor loading value of each item is greater than 0.5 . The average variance extracted (AVE) values are 0.604 and $0.510(>0.5)$ and composite reliability $(\mathrm{CR})$ values are 0.753 and $0.806(>0.7)$. All these indicate that these two scales both have good reliability and validity.

3) CWB scale

CWB scale we used is developed by Rees had based on the scale of Robinson and Bennett (2000), which has 12 items [16]. According to our situation and on the basis of this study, we deleted 4 items. Using Likert scale 5 point scoring method to measure employees CWB frequency (1-never, 5-always). Higher scores indicate that participants have counterproductive behavior more frequently. Reliability coefficient (Cronbach's alpha) is $0.863(>0.7)$ and factor loading value of each item is greater than 0.5 . The average variance extracted (AVE) value is $0.553(>0.5)$ and composite reliability $(\mathrm{CR})$ value is $0.867(>0.7)$. All these indicate that the CWB scale has good reliability and validity.

4) Leaders' emotional intelligence scale

Leaders' emotional intelligence scale (WLEIS) we used is developed by Wong and Law(2002), which has 16 items [17]. According to our situation and on the basis of this study, we put the "I" to "my leadership", and removed some redundant items. Finally, we get a revised version of the scale which has 14 items. It is 5 point Likert scoring (1-strongly disagree, 5-strongly agree). Getting higher scores shows that the leaders have higher emotional intelligence. Reliability coefficient (Cronbach's alpha) is $0.877(>0.7)$ and factor loading value of each item is greater than 0.5 . The average variance extracted (AVE) value is $0.6461(>0.5)$ and composite reliability $(\mathrm{CR})$ value is $0.9156(>0.7)$. All these indicate that the leaders' emotional intelligence scale has good reliability and validity.

\section{Data Analysis and Results}

Refer to the method to test the "moderated mediator" model by Wen and Zhang [18], we use SPSS statistics 
software to analyze data to explore the mediation role of emotional labor (surface and deep acting) and the moderating role of leaders' emotional intelligence. The test results are shown in Table 1 and Table 2.

Table 1 shows: In model 1, we set CWB as dependent variables, control variables (gender, age, etc.), independent variables (psychological capital) and moderator (leaders' emotional intelligence) as the independent variable, and make regression analysis. The coefficient of independent variables (psychological capital) is significant $(\beta=-0.348, p<0.001)$, showing that the service employees' psychological capital has a significant negative impact on CWB and it supports the H1. In model 2, we set surface acting as dependent variables, control variables (gender, age etc.), independent variables (psychological capital) and moderator (leaders' emotional intelligence) as the independent variable, and make regression analysis. The coefficient of independent variables (psychological capital) is significant $(\beta=0.567, p<0.001)$, showing that the service employees' psychological capital has a significant positive impact on surface acting. In model 3, we set CWB as dependent variables, control variables (gender, age, etc.), independent variables (psychological capital), moderator (leaders' emotional

Table 1. The mediation role of surface acting and the moderating role of leaders' emotional intelligence.

\begin{tabular}{|c|c|c|c|c|c|}
\hline & \multirow[b]{2}{*}{ Variable } & \multicolumn{4}{|c|}{ Dependent Variable } \\
\hline & & Model 1 & Model 2 & Model 3 & Model 4 \\
\hline \multirow{5}{*}{ Control Variable } & Gender & -0.007 & 0.022 & -0.007 & -0.006 \\
\hline & Age & $0.122^{* *}$ & 0.112 & $0.126^{* *}$ & $0.127^{* *}$ \\
\hline & Work Experience & -0.078 & -0.040 & -0.079 & -0.079 \\
\hline & Position & -0.028 & -0.007 & -0.028 & -0.028 \\
\hline & Industry & $0.074^{* *}$ & 0.027 & $0.074^{* *}$ & $0.074^{* *}$ \\
\hline Independent Variable & Psychological Capital & $-0.348^{* * *}$ & $0.567^{* * *}$ & $-0.332^{* * *}$ & $-0.336^{* * *}$ \\
\hline Mediator & Surface Acting & & & -0.030 & -0.149 \\
\hline Moderator & Leaders' Emotional Intelligence & $-0.544^{* * *}$ & $-0.880^{* * *}$ & $-0.570^{* * *}$ & -0.847 \\
\hline Interaction Item & Surface acting ${ }^{*}$ Leaders' Emotional Intelligence & & & & 0.261 \\
\hline
\end{tabular}

Table 2. The mediation role of deep acting and the moderating role of leaders' emotional intelligence.

\begin{tabular}{|c|c|c|c|c|c|}
\hline & \multirow[b]{2}{*}{ Variable } & \multicolumn{4}{|c|}{ Dependent Variable } \\
\hline & & Model 1 & Model 2 & Model 3 & Model 4 \\
\hline \multirow{5}{*}{ Control Variable } & Gender & -0.007 & 0.005 & -0.002 & -0.015 \\
\hline & Age & $0.122^{* *}$ & $-0.080^{*}$ & 0.039 & -0.001 \\
\hline & Work Experience & -0.078 & 0.059 & -0.017 & -0.002 \\
\hline & Position & -0.028 & -0.011 & -0.039 & 0.006 \\
\hline & Industry & $0.074^{* *}$ & $-0.052^{* *}$ & 0.020 & 0.018 \\
\hline Independent Variable & Psychological Capital & $-0.348^{* * *}$ & $0.376^{* * *}$ & 0.042 & $0.399^{* * *}$ \\
\hline Mediator & Deep Acting & & & $-1.038^{* * *}$ & $-8.487^{* * *}$ \\
\hline Moderator & Leaders' Emotional Intelligence & $-0.544^{* * *}$ & $0.600^{* * *}$ & 0.079 & $-4.874^{* * *}$ \\
\hline Interaction Item & Deep Acting ${ }^{*}$ Leaders' Emotional Intelligence & & & & $11.842^{* * *}$ \\
\hline
\end{tabular}

${ }^{*} p<0.05,{ }^{*} p<0.01,{ }^{* * *} p<0.001$. 
intelligence) and mediator(surface acting) as the independent variable, and make regression analysis. The coefficient of mediator (surface acting) is not significant $(\beta=-0.030, p>0.05$ ), showing that the service employees' psychological capital doesn't have a significant negative impact on surface acting, suggesting that for service workers, effect of surface acting on CWB is not significant. So the mediation role of surface acting between psychological capital and CWB is not significant, against H2a. In model 4, we set CWB as dependent variables, control variables (gender, age etc.), independent variables (psychological capital), moderator (leaders' emotional intelligence) and interaction item (surface acting * leaders' emotional intelligence) as the independent variable, and make regression analysis. The coefficient of interaction item(surface acting*leaders' emotional intelligence) is not significant $(\beta=0.261, p>0.05)$, showing that interaction item cannot have a significant impact on CWB, suggesting that for service workers, effect of the moderating role of leaders' emotional intelligence between surface acting and CWB is not significant which is against H3a.

We believe that the reason why the above assumption doesn't hold in this study is that participants selected are mostly young workers who are in the early career. They work more enthusiastic, and are eager to get someone else's appreciation, which will minimize their negative behavior in the work process. Thus, despite doing surface acting, they will not produce more CWB. This is the reason why H2a doesn't establish. For the same reason, younger workers are more attention to their own future career development. Their behavior is more influenced by themselves, so the moderating role of leaders' emotional intelligence is not significant, which is why H3a not established. In addition, we selected samples are distributed in Jilin Province, taking into account that there are different culture and values in the different regions [19], so for the other provinces and cities if the study conclusions are equally applicable should be further verified.

Table 2 shows: In model 5, we set deep acting as dependent variables, control variables (gender, age, etc.), independent variables (psychological capital) and moderator (leaders' emotional intelligence) as the independent variable, and make regression analysis. The coefficient of independent variables (psychological capital) is significant $(\beta=0.376, p<0.001)$, showing that the service employees' psychological capital plays a significant positive impact on deep acting. In model 6 , we set CWB as dependent variables, control variables (gender, age. etc.), independent variables (psychological capital), moderator (leaders' emotional intelligence) and mediator (deep acting) as the independent variable, and make regression analysis. The coefficient of mediator(deep acting) is significant $(\beta=-1.038, p<0.001)$, showing that the service employees' deep acting has a significant negative impact on CWB, suggesting that for service workers, effect of deep acting on CWB is significant. So the mediation role of deep acting between psychological capital and CWB is significant, supporting H2b. In model 7, we set CWB as dependent variables, control variables (gender, age etc.), independent variables (psychological capital), moderator (leaders' emotional intelligence), mediator (deep acting) and interaction item (deep acting * leaders' emotional intelligence) as the independent variable, and make regression analysis. The coefficient of interaction item (deep acting ${ }^{*}$ leaders' emotional intelligence) is significant $(\beta=11.842, p<0.001$ ), showing that interaction item have a significant positive impact on CWB, suggesting that for service workers, effect of the moderating role of leaders' emotional intelligence between deep acting and CWB is significant, supporting $\mathrm{H} 3 \mathrm{~b}$.

\section{Conclusions and Suggestions}

\subsection{Conclusions}

The purpose of this study is to explore the antecedent variables of counterproductive work behavior in service industry. In particular, we delved into the mediation role of emotional labor (surface and deep acting) between psychological capital and CWB, and the moderating role of leaders' emotional intelligence. From this study, we find:

1) The service employees' psychological capital has a significant negative impact on CWB. Employees with high psychological capital are more difficult to produce CWB; on the contrary, staff who with low psychological capital will be prone to produce CWB.

2) The mediation role of surface acting between psychological capital and CWB is not significant.

3) The mediation role of deep acting between psychological capital and CWB is significant. Employees whose psychological capital is high are more likely to be deep acting and more difficult to produce CWB. Conversely, low psychological capital employees are unlikely to choose deep acting and still be prone to produce CWB.

4) The moderating role of leaders' emotional intelligence between surface acting and CWB is not significant. 
5) The moderating role of leaders' emotional intelligence between deep acting and CWB is significant. For the services employees, deep acting produces a stronger negative effect on the CWB in high emotional intelligence leadership organization. Conversely, the effect will be weaker. That is, the higher the leaders' emotional intelligence is, the higher the tendency to do deep acting and suppress CWB in services industry will be.

\subsection{Management Suggestions}

1) For service companies, during the staff recruitment, candidates' psychological level of capital should be focused on and tested. Companies should try selecting candidates who have high degree of psychological capital [20]. The level of employees' psychological capital will impact them work behavior. Thus, on the basis of a high degree of personal, job and organization matching, companies should choose one who is more healthy, positive and doesn't afraid of setbacks, on the purpose of reduce the possibility to produce CWB and to disorganize the organization in the future.

2) For service companies, in training process, they can develop additional staff trainings about psychological capital [21]. Since the employees' psychological capital not only affect the generation of CWB directly, but also affect CWB by way of deep acting indirectly. Therefore, for employees, the development of psychological capital is essential. Companies could add additional training to develop employees' psychological capital, such as sharing successful experiences, quality development, the establishment of a learning organization, optimistic attribution training, role models and other methods to make them more positive attitude. Then they will work more positively and reduce the possibility to produce CWB. At the same time, they will enhance the quality and productivity of work. For enterprises, it will create more substantial in the future.

3) For service companies, leaders should pay more attention to human care in the work process [22]. They should improve the ability to manage employees' emotional, psychologic and behavior. In the high emotional intelligence organization, negative effect on the CWB from deep acting is strong, the higher the leaders' emotional intelligence, the higher the tendency to do deep acting and suppress CWB. Therefore, the leadership in the work process should always understand and care about staff to make them feel the concern from company. More attention and understanding will help them to make their business objectives as their responsibility, to do their own feelings and external performance consistency, thereby to reduce the probability of employees' CWB and to promote the company healthy, effective and sustainable development.

\section{Acknowledgements}

Thanks to MOE (Ministry of Education in China) Project of Humanities and Social Sciences (Project No. 12YJC 790193).

\section{References}

[1] Yu, H.X. (2013) Structural Dimensions and Influencing Factors of Employees, Counterproductive Behavior. Working Paper, Nanjing University of Science and Technology, Nanjing.

[2] Bennett, R.J. and Robinson, S.L. (2000) Development of a Measure of Workplace Deviance. Journal of Applied Psychology, 85, 349-360. http://dx.doi.org/10.1037/0021-9010.85.3.349

[3] Fine, S. (2012) Estimating The Economic Impact of Personnel Selection Tools on Counterproductive Work Behaviors. Economics and Business Letters, 1, 1-9. http://dialnet.unirioja.es/servlet/articulo?codigo $=4125813$

[4] Hafidz, S.W.M., Hoesni, S.M. and Fatimah, O. (2012) The Relationship between Organizational Citizenship Behavior and Counterproductive Work Behavior. Asian Social Science, 8, 32-37. http://dx.doi.org/10.5539/ass.v8n9p32

[5] Henle, C.A. (2005) Predicting Workplace Deviance from the Interaction between Organizational Justice and Personality. Journal of Managerial Issues, 17, 247-263. http://www.jstor.org/stable/40604498

[6] Li, F.W., Yuan, Z.Y. and Li, Y.J. (2012) Effects of Work Environment Stressors on Coalmine Employees' Counter-Productive Work Behavior and Safety Outcome. China Safety Science Journal, 22, 20-26. http://www.cnki.com.cn/Article/CJFDTotal-ZAQK201206005.htm

[7] Liu, Y.X., Zhang, J.W., Li, C.Q. and Peng, K.P. (2013) An Experimental Study on the Psychological Mechanism of Workplace Ostracism's Effects on Counterproductive Work Behavior. China Soft Science, 10, 157-167.

[8] Avey, J.B., Reichard, R.J., Luthans, F. and Mhatre, K.H. (2011) Meta-Analysis of the Impact of Positive Psychological Capital on Employee Attitudes, Behaviors, and Performance. Human Resource Development Quarterly, 22, 127-152. 
http://onlinelibrary.wiley.com/doi/10.1002/hrdq.20070

[9] Yan, W. (2010) Effect of Employees' Proactive Personality and Mental Capital on Qrganizational Citizenship Behavior and Counterproductive Behavior. Working Paper, Harbin Normal University, Harbin.

[10] Chen, D. (2008) Research on Emotional Labor, Job Satisfaction and Job Performance of Service Workers. Working Paper, Shandong University, Jinan.

[11] Liu, H. (2012) Can Emotional Labor Lead to Counter-Productive Behavior? Mediation Role of Emotional Exhaustion and Psychological Capital. Working Paper, Shanxi Normal University, Xi'an.

[12] Mayer, J.D., Caruso, D.R. and Salovey, P. (1999) Emotional Intelligence Meets Traditional Standards for an Antelligence. Intelligence, 27, 267-298. http://www.sciencedirect.com/science/article/pii/S0160289699000161

[13] Tang, C.Y. and Pan, Y. (2012) Cross-Layer Analysis of the Impact of Leadership Emotional Intelligence on Organizational Identification and Organizational Citizenship Behavior. Nankai Business Review, 13, 115-124.

[14] Zhou, P. and Jiang, X.Z. (2013) The Empirical Research of State-Owned Enterprise Managers, Working Pressure and Job Satisfaction: The Moderating Effects of Psychological Capital. East China Economic Management, 27, 134-137.

[15] Si, Y.Y. (2010) Job Satisfaction Study Guides on Emotional Labor. Working Paper, Henan University, Kaifeng.

[16] Dalal, R.S., Lam, H., Weiss, H.M., Welch, E.R. and Hulin, C.L. (2009) A Within-Person Approach to Work Behavior and Performance: Concurrent and Lagged Citizenship-Counterproductivity Associations, and Dynamic Relationships with Affect and Overall Job Performance. Academy of Management, 52, 1051-1066. http://dx.doi.org/10.5465/AMJ.2009.44636148

[17] Wong, C.S., Law, K.S. and Wong, P.M. (2004) Development and Validation of a Forced Choice Emotional Intelligence Measure for Chinese Respondents in Hong Kong. Asia Pacific Journal of Management, 21, 535-559. http://dx.doi.org/10.1023/B:APJM.0000048717.31261.d0

[18] Wen, Z.L., Zhang, L. and Hou, L.T. (2006) Mediated Moderator and Moderated Mediator. Acte Psychologica Sinica, 38, 448-452. http://www.cnki.com.cn

[19] Lv, S.S. (2013) Corporate Culture under the Influence of Regional Culture. Working Paper, Shandong Normal University, Jinan.

[20] Li, Y. (2012) Psychological Capital Theory in Human Resource Management. People's Tribune, 11, 64-65.

[21] Zhang, J. and Zhang, Y. (2010) Psychological Capital Development and Human Resources Management of Knowledge employee. Human Resource Management, 10, 94-95.

[22] Ran, L.Y. and Wan, C.L (2009) The Development of Employees' Psychological Capital from the Perspective of Human Resource Management. Manager' Journal, 17, 191. 